\title{
Pig transgenesis by Sleeping Beauty DNA transposition
}

Jakobsen, Jannik E.; Li, Juan; Kragh, Peter M.; Moldt, Brian; Lin, Lin; Liu, Ying; Schmidt, Mette; Winther, Kjeld D.; Schyth, Brian Dall; Holm, Ida E.

Total number of authors:

16

Published in:

Transgenic Research

Link to article, DOI:

$10.1007 / \mathrm{s} 11248-010-9438-\mathrm{x}$

Publication date:

2011

Link back to DTU Orbit

Citation (APA):

Jakobsen, J. E., Li, J., Kragh, P. M., Moldt, B., Lin, L., Liu, Y., Schmidt, M., Winther, K. D., Schyth, B. D., Holm, I. E., Vajta, G., Bolund, L., Callesen, H., Jørgensen, A. L., Nielsen, A. L., \& Mikkelsen, J. G. (2011). Pig transgenesis by Sleeping Beauty DNA transposition. Transgenic Research, 20(3), 533-545.

https://doi.org/10.1007/s11248-010-9438-x

\section{General rights}

Copyright and moral rights for the publications made accessible in the public portal are retained by the authors and/or other copyright owners and it is a condition of accessing publications that users recognise and abide by the legal requirements associated with these rights.

- Users may download and print one copy of any publication from the public portal for the purpose of private study or research.

- You may not further distribute the material or use it for any profit-making activity or commercial gain

- You may freely distribute the URL identifying the publication in the public portal

If you believe that this document breaches copyright please contact us providing details, and we will remove access to the work immediately and investigate your claim 
Editorial Manager(tm) for Transgenic Research Manuscript Draft

Manuscript Number: TRAG1116R3

Title: Pig transgenesis by Sleeping Beauty DNA transposition

Article Type: Original research papers

Section/Category: Animal Section

Keywords: Pig transgenesis

Somatic cell nuclear transfer

Genetic engineering

Sleeping Beauty DNA transposition

DNA transposase

Systemic gene expression

Corresponding Author: Dr. Jacob Giehm Mikkelsen, Ph.D.

Corresponding Author's Institution: University of Aarhus

First Author: Jannik E Jakobsen

Order of Authors: Jannik E Jakobsen; Juan Li; Peter M Kragh; Brian Moldt; Lin Lin; Ying Liu; Mette Schmidt; Kjeld D Winther; Brian D Schyth; Ida E Holm; Gabor Vajta; Lars Bolund; Henrik Callesen; Arne L Jørgensen; Anders L Nielsen; Jacob G Mikkelsen

Abstract: Modelling of human disease in genetically engineered pigs provides unique possibilities in biomedical research and in studies of disease intervention. Establishment of methodologies that allow efficient gene insertion by non-viral gene carriers is an important step towards development of new disease models. In this report, we present transgenic pigs created by Sleeping Beauty DNA transposition in primary porcine fibroblasts in combination with somatic cell nuclear transfer by handmade cloning. Göttingen minipigs expressing green fluorescent protein are produced by transgenesis with DNA transposon vectors carrying the transgene driven by the human ubiquitin C promoter. These animals carry multiple copies (from 8 to 13) of the transgene and show systemic transgene expression. Transgene-expressing pigs carry both transposase-catalyzed insertions and at least one copy of randomly inserted plasmid DNA. Our findings illustrate critical issues related to DNA transposon-directed transgenesis, including coincidental plasmid insertion and relatively low Sleeping Beauty transposition activity in porcine fibroblasts, but also provide a platform for future development of porcine disease models using the Sleeping Beauty gene insertion technology. 


\section{Pig transgenesis by Sleeping Beauty DNA transposition}

Jannik E. Jakobsen ${ }^{1}$, Juan $\mathrm{Li}^{2}$, Peter M. Kragh ${ }^{1,2}$, Brian Moldt ${ }^{1}$, Lin Lin ${ }^{2}$, Ying Liư ${ }^{2}$, Mette Schmidt ${ }^{3}$, Kjeld Dahl Winther ${ }^{4}$, Brian Dall Schyth ${ }^{5}$, Ida E. Holm ${ }^{6,7}$, Gábor Vajta ${ }^{2}$, Lars Bolund ${ }^{1}$, Henrik Callesen ${ }^{2}$, Arne Lund Jørgensen ${ }^{1}$, Anders Lade Nielsen ${ }^{1}{ }$, and Jacob Giehm Mikkelsen ${ }^{1} *$

${ }^{1}$ Department of Human Genetics, University of Aarhus, DK-8000 Aarhus C, Denmark

${ }^{2}$ Department of Genetics and Biotechnology, Faculty of Agricultural Sciences, University of Aarhus, DK8830 Tjele, Denmark

${ }^{3}$ Department of Veterinary Reproduction and Obstetrics, Faculty of Life Sciences, University of Copenhagen, DK-1870 Frederiksberg C, Denmark

${ }^{4}$ Danish Agriculture and Food Council, Knowledge Center on Pig production, DK-1609 Copenhagen V, Denmark

${ }^{5}$ National Veterinary Institute, Technical University of Denmark, DK-8200 Aarhus N, Denmark

${ }^{6}$ Department of Pathology, Randers Hospital, DK-8900 Randers, Denmark

${ }^{7}$ Danish Neuroscience Center, Aarhus University Hospital, DK-8000 Aarhus C

* These authors contributed equally to this work

Running title: DNA transposon-mediated pig transgenesis

Word count abstract: 169

Word count text: 4728

*Corresponding author

Jacob Giehm Mikkelsen, Department of Human Genetics, University of Aarhus, Wilh. Meyers Allé 1240, DK-8000 Aarhus C, Denmark. Phone: +45 89421651. Email: giehm@humgen.au.dk 


\section{ABSTRACT}

Modelling of human disease in genetically engineered pigs provides unique possibilities in biomedical research and in studies of disease intervention. Establishment of methodologies that allow efficient gene insertion by non-viral gene carriers is an important step towards development of new disease models. In this report, we present transgenic pigs created by Sleeping Beauty DNA transposition in primary porcine fibroblasts in combination with somatic cell nuclear transfer by handmade cloning. Göttingen minipigs expressing green fluorescent protein are produced by transgenesis with DNA transposon vectors carrying the transgene driven by the human ubiquitin $\mathrm{C}$ promoter. These animals carry multiple copies (from 8 to 13) of the transgene and show systemic transgene expression. Transgene-expressing pigs carry both transposase-catalyzed insertions and at least one copy of randomly inserted plasmid DNA. Our findings illustrate critical issues related to DNA transposon-directed transgenesis, including coincidental plasmid insertion and relatively low Sleeping Beauty transposition activity in porcine fibroblasts, but also provide a platform for future development of porcine disease models using the Sleeping Beauty gene insertion technology. 


\section{INTRODUCTION}

Disease models in large animals play an increasing role in biomedical research and have important implications for the development of diagnostic tools and novel treatment of human diseases. Due to the anatomical and physiological similarities between humans and the pig, genetically engineered porcine disease models may be expected to recapitulate human pathophysiology more faithfully than do corresponding disease models in rodents. Also, a longer life-span may allow studies of chronic diseases, and a human-size body may enable studies of surgical intervention.

Pigs that are predisposed for a certain monogenic disease can be created by genetic engineering of the pig genome, in the least complicated approach by insertion of a proposed disease gene which may in a dominant fashion trigger development of the disease. Transgenesis in pigs has previously been achieved by transferring the transgene to oocytes or early embryos by pronuclear injection of foreign DNA (Hammer et al. 1985; Hirabayashi et al. 2001; Nottle et al. 2001), transduction with retro- and lentiviral vectors injected into the perivitelline space of the oocyte (Cabot et al. 2001; Hofmann et al. 2003; Whitelaw et al. 2004) or, alternatively, by sperm-mediated gene transfer (Naruse et al. 2005; Webster et al. 2005). With the successful cloning of animals by somatic cell nuclear transfer (SCNT), it is now possible to produce transgenic pigs from genetically engineered somatic donor cells. In SCNT, reported for a variety of animal species including the mouse (Wakayama et al. 2000; Wakayama and Yanagimachi 1999), the sheep (Wilmut et al. 1997), the cow (Cibelli et al. 1998; Kato et al. 1998; Kubota et al. 2000), and the pig (Betthauser et al. 2000; Onishi et al. 2000; Polejaeva et al. 2000), the nucleus from a single differentiated somatic cell is transferred into an enucleated oocyte (unfertilized egg cell), and the reconstructed embryo is subsequently transferred to a surrogate mother. This procedure allows modification of the somatic donor cell in culture by transgene insertion or introduction of loss-offunction gene knockout mutations by homologous recombination. We have previously produced transgenic pig blastocysts by SCNT using a simplified and improved cloning procedure designated 
handmade cloning (HMC) (Du et al. 2007; Kragh et al. 2004) and recently developed Göttingen minipigs expressing a randomly inserted human APP gene containing an Alzheimer's disease-causing dominant mutation (Kragh et al. 2009).

Permanent genetic modification of somatic donor cells for SCNT has been achieved by random genomic insertion of plasmid DNA (Hyun et al. 2003; Kragh et al. 2009; Kragh et al. 2004; Watanabe et al. 2005) or by genomic integration of transduced retroviral or lentiviral vectors (Lai et al. 2002; Park et al. 2001; Park et al. 2002). In both non-viral and viral approaches inclusion of a drug resistance gene in the transgene-encoding vectors allows selection for cells containing the integrated vector. Random insertion of plasmid DNA into the genome of somatic donor cells occurs as a result of breakage of the plasmid DNA. Breakage within the transgene cassette may result in drug-selected cell clones and eventually transgenic pigs that do not express the transgene. Moreover, randomly inserted plasmid DNA is thought to be more prone to formation of concatamers during the integration process which may affect gene expression (Garrick et al. 1998; Leahy et al. 1997). High gene transfer efficiency and genomic insertion of a defined genetic entity are major advantages of transgenesis by retro- and lentiviral vectors. However, both vector types preferentially target transcriptionally active regions of the genome (Mitchell et al. 2004; Schroder et al. 2002) and are, therefore, likely to insert near or into genes. Also, these technologies require classified laboratory facilities and extra precaution with respect to housing of the transgenic animals.

In this report, we describe the use of Sleeping Beauty (SB) DNA transposon-based vectors for creation of genetically engineered Göttingen minipigs expressing the green fluorescent protein (GFP) reporter gene. Transposable DNA elements are mobile genetic entities that integrate into genomic DNA in a transposition process catalyzed by the transposase enzyme encoded by the element itself. SB is a cut-and-paste DNA transposon belonging to the Tc1/mariner superfamily of transposon elements. SB was genetically reconstructed from fossil elements in the genome of salmoid fish (Ivics et al. 1997) and is 
actively mobilized in cells derived from a variety of vertebrate species (Izsvak et al. 2000). SB-derived vectors efficiently jump from plasmid DNA introduced into cells to chromosomal DNA and are inserted without particular preference for actively transcribed genes (Liu et al. 2005; Yant et al. 2005). The element has been explored for the use in therapeutic gene transfer (Izsvak and Ivics 2004; Liu et al. 2006; Mates et al. 2009; Mikkelsen et al. 2003; Ohlfest et al. 2004; Singh et al. 2008; Yant et al. 2000) and is widely used as a tool in animal transgenesis. SB-directed transgenesis is well-established in zebrafish (Davidson et al. 2003), and germline mutagenesis by microinjection of transposon DNA and transposaseencoding nucleic acids into fertilized oocytes has been established in the mouse (Dupuy et al. 2002; Mates et al. 2009) and the frog (Sinzelle et al. 2006; Yergeau et al. 2009).

The properties of SB as an efficient and genetically simple non-viral transgene delivery system facilitating gene insertion with a random integration profile make SB-derived vectors relevant tools for transgenesis also of larger animals. A routine use of transposons may be expected to improve the efficiency of cellular transgenesis and to reduce concatamer formation and integration of CpG-rich plasmid sequence (Clark et al. 2007a). By transfecting skin-derived porcine fibroblasts with plasmid DNA carrying the GFP reporter gene, we previously reported production of blastocysts harboring randomly inserted plasmid DNA (Kragh et al. 2004). Active transposition of SB-derived vectors in porcine fibroblasts has recently been documented (Clark et al. 2007b). Using the GFP gene as a reporter, we here combine SB-directed engineering of neonatal porcine fibroblasts with HMC-based SCNT and production of transgenic cloned pigs. We describe events of SB transposition leading to the production of transgenic cloned pigs with uniform GFP expression in all analyzed organs, but also describe potential critical issues on the path towards creating porcine disease models using the SB technology. 


\section{RESULTS}

\section{Generation of transgenic pigs by SCNT using SB transposon-modified neonatal porcine fibroblasts}

Production of transgenic pigs by SCNT is based on the genetic engineering of primary porcine cells prior to nuclear transfer. To investigate the potential use of SB-derived vectors in minipig transgenesis, we constructed a SB transposon vector, designated pSBT/cHS4.Ubi-GIN.cHS4, harboring a bicistronic gene cassette with a reporter gene encoding green fluorescent protein (GFP) linked to a neomycin resistance gene $\left(\right.$ neo $\left.^{r}\right)$ through an internal ribosomal entry site (IRES) (Fig. 1A). The human ubiquitin C promoter (Ubi) was utilized to drive expression, and the expression cassette was flanked on each side by 1.2-kb long $5^{\prime}$-HS4 chicken $\beta$-globin (cHS4) insulators, which have been shown to protect the genetic cargo of SB transposons from transcriptional silencing (Dalsgaard et al. 2009).

Transposition in neonatal porcine fibroblasts (NPFs) was carried out by co-transfecting pSBT/cHS4.Ubi-GIN.cHS4 with an expression construct, pCMV-HSB3, encoding the hyperactive HSB3 transposase variant. This transposase variant has previously been shown to increase levels of transposition more than 5-fold compared to the original SB10 transposase (Yant et al. 2004). By transfecting supercoiled transposon donor plasmid and HSB3-encoding plasmid in a 40:1 ratio (using 50 ng of pCMV-HSB3), the number of G418-resistant NPF colonies was increased 12 -fold relative to an experiment in which HSB3-expressing plasmid was replaced by the pUC19 plasmid (Fig. 1B). This suggested that the SB transposon was actively mobilized by the HSB3 transposase from transfected plasmid DNA and inserted into genomic DNA of NPFs derived from a newborn Göttingen minipig.

We next created a pool of clones consisting of a total of 80 independent G418-resistant NPF clones. The pool was expanded, and transgenic blastocysts were created by HMC. A total of 102 blastocysts were transferred to the surrogate sow. Eight pigs were born alive and one pig was stillborn, and none of the pigs showed any sign of abnormalities. Five of the pigs survived past weaning (Fig. 1C). 
Ear cuts from these five pigs (pigs \#6-9, and \#13) were analyzed for fluorescence under blue light, and four of the five pigs were found to express GFP (Fig. 1D; pigs \#6-8 and \#13). These findings were confirmed by fluorescence microscopy of cultured fibroblasts derived from the ear biopsies (data not shown). Furthermore, only fibroblasts derived from the four GFP-positive pigs survived 10 days of culturing in G418-containing medium, whereas fibroblasts from the GFP-negative pig proved not to be G418-resistant. These observations indicated that at least one intact GFP-IRES-neo ${ }^{r}$ cassette was present in four out of five pigs.

\section{Multiple integrations of the transgene cassette in GFP-expressing pigs}

To characterize the transgene cassette insertion in the cloned pigs, we first performed Southern blot analysis, using a neor probe, on genomic DNA isolated from blood samples. The genomic DNA was digested with Xbal, which cuts once in the transposon (in the GFP gene) and in the case of a random insertion in the plasmid region flanking the right IR of the transposon (Fig. 2A). Among the four GFPpositive pigs (\#6-8 and \#13), three different banding patterns were observed (Fig. 2B, lanes 2-4 and 6). The band patterns in lanes 2 and 3 were identical and suggested a total of 13 insertions. Hence, the two pigs (\#6 and \#7) originated from cells from the same NPF clone. Two of the pigs (\#8 and \#13), each containing eight insertions, had almost identical banding patterns except for two single bands (position marked with arrows in Fig. 2B) that varied between the two animals (Fig. 2B, lanes 4 and 6). These two pigs were most likely generated from the same NPF clone which happened to be polyclonal due to late SB insertions or, alternatively, due to re-mobilization of an inserted DNA transposon during clone development and selection. Interestingly, the GFP-negative pig (\#9) was indeed transgenic but contained only randomly inserted plasmid DNA, as indicated by the detection of a 4.5-kb fragment (Fig. 2B, lane 5). Our data suggested that the five pigs were derived from a total of three NPF clones selected among the 80 clones of the original pool. This lends support to the notion that a strong selection pressure is evident 
at one or more steps of the cloning procedure including expansion of pooled clones, generation of blastocysts, and/or embryo and fetal development.

The Southern blot analysis suggested that random plasmid insertion caused by plasmid breakage in the region outside the Xbal-flanked GIN cassette (resulting in a 4.5-kb fragment) occurred in all pigs but was prominent only in the GFP-negative pig. In this pig, the $4.5-\mathrm{kb}$ band was representative of two independent random insertions, which was confirmed by the presence of two separate bands on a Southern blot, where enzymes cutting within the Ubi promoter and within the IRES sequence were used (data not shown).

We have previously found evidence of random insertion of transposase-encoding plasmid sequences in a transgenic cloned Göttingen minipig (J. E. Jakobsen, A. L. Jørgensen, A. L. Nielsen, J. G. Mikkelsen; unpublished observations). A sample of genomic DNA from this animal was utilized as a positive control in a PCR-based analysis of the presence of such sequences in the five transgenic pigs studied here. We did not find any evidence of integration of transposase-encoding plasmid in any of the five transgenic pigs (Fig. 2C, lanes 1-5 and 8-12) or a negative control (Fig. 2C; pig \#78, lanes 6 and 13), whereas PCR analysis of genomic DNA from the positive control pig showed evidence of the transposase gene (Fig. 2C; pig \#58, lanes 7 and 14).

\section{Evidence of transposase-directed gene insertion by analysis of integration sites in transgenic pigs}

To confirm that SB transposase-directed gene integration was a prevalent mechanism of insertion during transgenesis, we performed long distance inverse PCR (LDI-PCR) on one of the pigs (pig \#8) containing eight insertions to identify junction sites between transposon and genomic DNA. PCR amplification of genomic DNA digested with either BsrGl or BsrGl/Ndel resulted in a total of five amplicons, all of which

were found by sequence analysis to carry the hallmarks of a SB transposon insertion. Four of these insertions were unique and could be mapped to different genomic loci, all situated in intergenic regions 
of the pig genome (Fig. 3). In summary, our genetic analyses show that SB-directed transgenesis was achieved by gene insertion into intergenic regions.

\section{Systemic expression of transgenic GFP in pigs harboring multiple SB-directed insertions}

We sacrificed pig \#8 to carry out careful fluorescence imaging of the animal in comparison with an agematched animal as negative control. As shown in Fig. 4A through Q, GFP expression was detected in all seventeen analyzed tissues of the transgenic pig including brain, eye, skeletal muscle, heart, lung, liver, and skin. Some autofluorescence could be detected in the liver, heart, and rib bone of the control pig but fluorescence was still considerably stronger in the tissues from the transgenic pig (Fig. 4, panels B1/B2, G1/G2, and P1/P2). Heart and testis (Fig. 4, panels $G 2$ and H2) did not show similar uniform expression of GFP compared to the remaining organs, and the fat layer covering the heart had increased fluorescence compared to the smooth heart muscle (Fig. 4, panels G1 and G2), whereas fluorescence in the epididymis was considerably higher than in the testis (Fig. 4, panels $\mathrm{H} 1$ and $\mathrm{H} 2$ ). This pig contained a minimum of four and possibly more SB transposase-directed transgene insertions flanked by cHS4 insulators. It was not possible at this stage to determine the contribution of each of the insertions to the overall expression of GFP. The animals are currently being bred and future transgenic offspring will be analyzed for persistency of and differences in transgene expression. 


\section{DISCUSSION}

We describe here the production of transgenic cloned pigs by HMC-directed nuclear transfer using primary porcine fibroblasts modified by genomic insertion of a GFP-tagged Sleeping Beauty DNA transposon vector. By SB transposase-directed insertion of the GFP marker gene, we established Göttingen minipigs with systemic expression of the transgene. Hence, all of seventeen analyzed tissues, including brain, eye, muscle, heart, lung, liver, and skin, derived from pigs containing SB vector insertions were found to express GFP by fluorescence imaging.

SB facilitates efficient gene insertion in a wide panel of cell types (Izsvak et al. 2000) and represents an attractive non-viral approach for gene delivery and insertion in both gene therapy applications and animal transgenesis. The level of stable transfection mediated by SB in a particular cell type is under influence of the DNA transfection efficiency as well as the SB mobilization rate, both of which may vary considerably between cell types. SB transposition is supported by cellular factors like the DNA-bending protein HMGB1 (Zayed et al. 2003) and is influenced by the transposase concentration, which is likely to vary between cell types depending on efficacy of DNA uptake and expression vector design (Mikkelsen et al. 2003). In NPFs, the level of stable transfection obtained with the HSB3 transposase was significantly increased over background but was relatively low compared to levels that we routinely measure in murine or human cell lines. As the NPFs were quite efficiently transfected with at least $50 \%$ of the cells transiently expressing the transgene (data not shown), our findings most likely reflect suboptimal transposition rates in NPFs. Still, the HSB3 transposase increased the level of gene insertion (as measured by the number of drug-resistant colonies) 12-fold relative to the negative control in which pUC19 plasmid was co-transfected with the transposon donor plasmid. In analogy, previous work by Clark and co-workers showed that the SB11 transposase variant increased colony formation in pig fetal fibroblasts 2.5 -fold over fibroblasts transfected with plasmid encoding an inactive transposase variant (Clark et al. 2007b). To create a procedure for production of transposon-tagged transgenic pigs 
with reduced risk of inserting the transposase gene in the animals, we utilized low amounts of SB transposase-encoding plasmid (50 ng plasmid) during in vitro manipulation of NPFs. Evidence of transposase-directed transgene insertion was obtained in the GFP-transgenic litter. Hence, in one of the pigs, for which the SB insertions were carefully mapped, at least four SB transposase-directed insertions out of a total of eight insertions could be detected.

Integrating viral vectors are directed towards transcriptionally active regions in the genome due to specific interactions between cellular and viral proteins (Ciuffi et al. 2005). One of the advantages of SB transposon vectors is the random integration profile (Liu et al. 2005; Staunstrup et al. 2009; Yant et al. 2005). Thus, SB vectors are less likely to target genes but may be more vulnerable to transcriptional silencing when inserted in heterochromatin. In cell lines the immediate silencing of SB vectors after insertion can be relieved by flanking the transgene with cHS4 insulators (Dalsgaard et al. 2009), and downstream analyses of the SB-transgenic pigs will assist in documenting the potential benefits of transgene insulation.

Although HSB3 mediated increased stable transfection in NPFs, at least one random insertion containing remnants of the transposon donor plasmid backbone was identified in each of the five pigs. Notably, one of the pigs was found to contain two random insertions only. This pig did not express the transgene, suggesting that the two transgene cassettes were transcriptionally silenced or, as cannot be formally excluded, that the plasmid breakage point in both cases affected both genes of the transgene expression cassette at some point after initial selection.

Transposase-encoding plasmid could not be detected in any of the five transgenic pigs. This is an important finding since continued expression of the transposase could potentially facilitate transposon re-mobilization and re-insertion, resulting in reduced overall stability of the pig model. Although this aspect is rarely experimentally addressed in reports describing transposon-directed gene delivery, methods for co-delivery of transposon donor plasmid with in vitro-synthesized mRNA encoding the 
transposase to somatic cells have been described (Wilber et al. 2006) and may be applicable in protocols of SB-directed pig transgenesis. Also, the use of in vitro-transcribed mRNA as a source of transposase has been successful in early embryos of frog (Sinzelle et al. 2006), zebrafish (Davidson et al. 2003), and mouse (Dupuy et al. 2002).

Cloning based on a pool consisting of 80 NPF clones resulted in birth of one set of genetically identical twins and a pair of pigs originating from a single NPF clone. This indicates that the genetic engineering process and cloning by HMC-directed SCNT is accompanied by a selection pressure. Whether this pressure is in effect during in vitro cell expansion or during blastocyst or embryo development is not clear. Also, it remains a matter of speculation whether these observations reflect any toxicity related to the actions of the SB transposase. Despite the fact that four of the five pigs contained at least 8 insertions, we find it unlikely that these clones had a selective advantage due to their high copy numbers. However, our data suggest that a cloning strategy based on expanded pools is more likely to succeed, less labor-intensive, and cheaper than cloning using individual clones. Moreover, by growing pools rather than individual drug-resistant clones we could minimize the number of cell cycles and limit the risk of chromosomal aberrations during in vitro culturing of the fibroblasts.

Retro- and lentiviral vectors are established potent tools for stable modification of porcine somatic donor cells for SCNT (Lai et al. 2002; Park et al. 2001; Park et al. 2002) and have been successfully used for transgene delivery to porcine embryos (Cabot et al. 2001; Hofmann et al. 2003; Whitelaw et al. 2004). SB-directed transgenesis combined with SCNT and HMC represents a nonviral alternative that offers insertion of a defined genetic unit, strong systemic transgene expression, and possibilities of multicopy transgene insertion. Still, the moderate efficiency of the cloning procedure requires that a significant amount of nuclear transfers is performed. In our hands, 102 blastocysts (resulting from more than 250 reconstructed embryos) were transferred to the surrogate sow to create a transgenic litter of eight piglets. Five of these pigs survived past weaning, whereas three pigs died 
without signs of any macroscopic malformations, as suggested by the post-mortem examination. Reports of lentiviral transgenesis based on injection of viral particles into the perivitelline space of single-cell embryos have shown birth of as many as 34 transgenic pigs from 244 zygotes treated with human immunodeficiency virus-derived vectors (Hofmann et al. 2003) and 37 transgenic pigs from a total of 120 zygotes treated with vectors based on equine infectious anaemia virus (Whitelaw et al. 2004). Notably, a transposon-based approach does not require classified laboratory facilities for genetic engineering of somatic cells, production of early embryos, or housing of the animals. Our protocol may be further refined for example by use of the highly potent SB100X transposase (Mates et al. 2009) encoded by trace amounts of transfected plasmid DNA or in vitro-transcribed RNA. We believe that the SB system combined with SCNT has the potential of becoming a preferred tool for introduction of dominant mutations or shRNA genes in the porcine genome and that this approach will prove to be of high value for creation of disease models in the pig. 


\section{MATERIALS AND METHODS}

\section{Vector construction}

The transposon donor vector, pSBT/cHS4.Ubi-GIN.cHS4, was generated by inserting PCR-amplified 1.2-kb cHS4 insulators into linkers flanking the gene expression cassette in the vector pSBT/Ubi-GIN. This vector contains a GFP-IRES-neo ${ }^{r}$ (GIN) cassette driven by the human ubiquitin C promoter (Ubi) and was derived from pSBT/RSV-FGIP (Moldt et al. 2008). The GFP sequence, originally derived from peGFP.N1 (Clontech, Mountain View, CA, USA), contained a Flp recognition sequence (FRT) inserted between the start codon and the remaining part of the eGFP gene, as described in (Moldt et al. 2008). This chimeric variant of the gene is here simply designated 'GFP'. pSBT/Ubi-GIN was generated by replacing the SV40 promoter of pSBT/SV40-FGIP (similar, except for the promoter, to pSBT/RSV-FGIP) with the human ubiquitin C promoter PCR-amplified from pUbiC-Jun (Schorpp et al. 1996) using the following two primers: 5'GTAAACGCGTAGATCTGGCCTCCGCGCC-3' and 5'-CGGTCCATGGAAGCTTCGTCTAACAAAAAAG-3'. The fragment was inserted into Mlul/Ncol-digested pSBT/SV40-FGIP. The IRES-puro cassette of pSBT/UbiFGIP was replaced with an IRES-neo ${ }^{r}$ cassette PCR-amplified from pCMV-Bipep (Tolstrup et al. 2001) creating pSBT/Ubi-GIN. pCMV-HSB3 was previously described (Yant et al. 2004).

\section{Generation of transgenic porcine fibroblasts by transfection of SB transposon vectors}

Neonatal porcine fibroblasts (NPFs) were cultured from ear biopsies of newborn Göttingen minipig no. 74113 (Ellegaard Göttingen Minipigs A/S, Soroe Landevej 302, DK-4261 Dalmose, Denmark) as previously described (Kragh et al. 2009). The cells were grown in DMEM to $50 \%$ confluence, trypsinized, and resuspended for further expansion prior to freezing of aliquots. For production of a transgenic litter, $2 \times$ $10^{5}$ fibroblasts were transfected in a in a $60-\mathrm{cm}^{2}$ dish (in $10 \mathrm{ml}$ medium) using $2 \mu \mathrm{g}$ of the pSBT/cHS4.UbiGIN.cHS4 transposon plasmid and $50 \mathrm{ng}$ pCMV-HSB3 or as control 50 ng pUC19 plasmid. $10 \mu$ FuGENE 6 
was used in the reaction mixture. On the following day, the cells were washed with PBS and subsequently cultured in G418-containing medium $(0.75 \mu \mathrm{g} / \mathrm{ml})$ for two weeks. A total of 80 colonies were pooled and grown for 9 days prior to SCNT by HMC.

\section{Handmade cloning (HMC) using SB-treated NPFs}

Handmade cloning was performed as previously described (Du et al. 2007). Briefly, oocytes with partially digested zonae pellucidae were enucleated by oriented bisection according to the polar body position. For each oocyte, the part without chromatin, i.e. the cytoplast, was collected and electrofused with one transgenic fibroblast modified by SB to carry the cHS4.Ubi-GIN.cHS4 cassette. Another cytoplast was then electrofused with each cytoplast-fibroblast pair during a second fusion round which also activated the reconstructed embryo. After 6 days the in vitro cultured embryos were developed into transgenic blastocysts. Day 5 and 6 blastocysts with clearly visible inner cell mass were surgically transferred to a Danish landrace sow on day 4 or 5 after weaning. Pregnancy in the surrogate sow was diagnosed by ultrasonography on day 21 and confirmed during later stages of the pregnancy. Pigs were delivered by natural birth on day 114 and raised by their surrogate mother. Pregnancy was established by transfer of 102 cHS4.Ubi-GIN.cHS4-transgenic blastocysts to the surrogate sow. Among nine delivered pigs, one was stillborn and five pigs (referred to as pigs \#6-9 and \#13) survived past weaning. The non-transgenic wildtype pig included as a negative control pig was designated \#78.

\section{Analysis of transgene expression}

5-mm ear cuts and fibroblasts derived from ear biopsies were analysed by fluorescense microscopy. Green fluorescent protein (GFP) was monitored with a $492 \mathrm{~nm}$ excitation filter and a $508 \mathrm{~nm}$ emission filter, exposing for $0.5 \mathrm{sec}$. Organs and tissues from selected transgenic pigs and control pigs were imaged using a Kodak Multispectral In-Vivo FX machine (Carestream Inc, New Haven, CT, USA). For each 
organ or tissue two images were acquired, one at white light (excitation: $0 \mathrm{~nm}$; emission: $600 \mathrm{~nm}$; exposure time: $0.175 \mathrm{sec}$; F-stop:22.14; no binning) and one by which GFP fluorescence was monitored by using the multi-wavelength function with a $480 \mathrm{~nm}$ excitation filter and a $535 \mathrm{~nm}$ emission filter, exposing for $1 \mathrm{sec}$. with f-stop: 2.51 and $2 \times 2$ binning. Every two images were acquired using the same field of view (FOV). After acquisition, pictures taken in full light were added a scale bar. The fluorescence emission picture was artificially coloured green in the Kodak IM Software v1.0 according to the signal detected using the specified filter set.

\section{Copy number analysis by Southern blotting}

Six $\mu \mathrm{g}$ of genomic DNA was digested with restriction enzymes, loaded on a $0.7 \%$ agarose gel and electrophoresed overnight at $1 \mathrm{~V} / \mathrm{cm}$. The DNA was transferred to a nylon membrane (Roche, Basel, Switzerland) by vacuum suction. During transfer, the DNA was nicked and denatured by $0.25 \mathrm{M} \mathrm{HCl}$ and 1.5 $\mathrm{M} \mathrm{NaCl}$ plus $0.5 \mathrm{M} \mathrm{NaOH}$, respectively. The membrane was prehybridized in 5 XSSPE $(0.75 \mathrm{M} \mathrm{NaCl}$, $0.05 \mathrm{M} \mathrm{NaH}_{2} \mathrm{PO}$, $0.005 \mathrm{M}$ EDTA), 5x Denhart (0.1\% Ficoll400, $0.1 \%$ polyvinylpyrrolidone, $0.1 \% \mathrm{BSA}$ ), 1 \%SDS, $50 \%$ formamide, $5 \%$ dextransulphate and single-stranded DNA carrier $(0.5 \mathrm{mg} / \mathrm{ml})$ overnight at $42{ }^{\circ} \mathrm{C}$. The DNA probe, a 670-bp fragment of the neomycin resistance gene, was labelled with $\mathrm{P}^{32}$-labelled CTP by random priming, heat-denatured, added to prehybridization solution, and incubated with the membrane overnight at $42{ }^{\circ} \mathrm{C}$. The membrane was washed in $2 \times$ SSPE for $2 \times 5$ min at $26{ }^{\circ} \mathrm{C}$, in $2 \times$ SSPE, 0.5 $\%$ SDS for $2 \times 15 \mathrm{~min}$ at $63{ }^{\circ} \mathrm{C}$, and in $0.2 \times \mathrm{SSPE}, 0.5 \%$ SDS for $15 \mathrm{~min}$ at $63^{\circ} \mathrm{C}$. The membrane was air-dried prior to X-ray film exposure.

\section{Detection of genomically integrated transposase gene by PCR}

To investigate whether or not the SB transposase-encoding helper plasmid had been incorporated into the genome of the SB-transgenic fibroblasts, we used PCR with two set of primers. The first primer pair 
(5'-GCTTAGGGTTAGGCGTTTTG-3' and 5'-GGTTATGTCGATATAGGACTCG-3') spanned part of the CMV promoter and the $5^{\prime}$ ORF in the transposase. The second primer pair (5'-GCCAGACTACGGTTTGCAAC- $3^{\prime}$ and 5'-CACCTTCCAGGGTCAAGGAAG-3') amplified the transposase ORF.

\section{Identification of SB vector insertion sites by long distance inverse PCR (LDI-PCR)}

Templates for amplification of junction sites between transposon and genomic DNA were generated as follows: $0.5 \mu$ genomic DNA was digested with either BsrGl alone or together with Ndel, purified on a GFX column and eluted in $40 \mu \mathrm{lddH_{2 }}$ O. After adjustment with dd $\mathrm{H}_{2} \mathrm{O}$ and $10 x \mathrm{~T} 4$ ligase buffer, T4 ligase was added, and the $500 \mu$ ligation mix was incubated at $16{ }^{\circ} \mathrm{C}$ overnight. Ligated DNA was purified on a

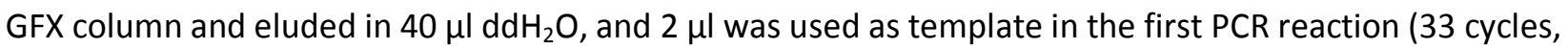
20 pmol primers and annealing temperature of $59^{\circ} \mathrm{C}$ ) using primers with recognition sequences within the right inverted repeat (5'-GTCCTGCTGGAGTTCGTGAC-3') and within the neo gene $\left(5^{\prime}\right.$ GGCACAGTCAACTTAGTGTATG-3'). Subsequently, $1 \mu \mathrm{l}$ of this PCR reaction was used as template in a nested PCR (30 cycles, 10 pmol primers and annealing temperature of $58.5^{\circ} \mathrm{C}$ ) using the primers 5'ATCACTCTCGGCATGGAC-3' and 5'-GATGTCCTAACTGACTTGCC-3'. The resulting PCR products were gelpurified and sequenced. 


\section{ACKNOWLEDGMENTS}

We thank Peter Angels for providing pUbiC-Jun. We thank Tina Fuglsang and Marianne Gregers Johansen for excellent technical assistance. The work by J.E.J. was carried out in the laboratory of A.L.J. This work was made possible through support from the Danish National Advanced Technology Foundation, the Lundbeck Foundation (grant no. R19-A2108), the Danish Research Agency (grant no. 274-05-0197), the Danish Medical Research Council, the Novo Nordisk Foundation, the Carlsberg Foundation, the Danish Cancer Society, the Danish Heart Association, Aage Bangs Foundation, the Augustinus Foundation, and the EU (EU-FP6-STREP, contract number 018961). B.M was funded by a grant from the Danish Cancer Society. 


\section{FIGURE LEGENDS}

Figure 1. Generation of GFP-transgenic pigs by insertion of insulated GFP-encoding SB vectors in porcine fibroblasts. (A) Schematic map of the SB transposon vector, pSBT/cHS4.Ubi-GIN.cHS4, used to create transgenic pigs. The borders of the transposon are indicated by grey arrows representing the left and right inverted repeats (LIR and RIR). The vector contains a transgene GFP-IRES-neo ${ }^{r}$ cassette flanked by 1.2-kb long 5'-HS4 chicken $\beta$-globin (cHS4) insulators. (B) Stable transfection efficiency in NPFs. The diagram depicts the number of G418-resistant colonies measured by co-transfection of NPFs with pSBT/cHS4.Ubi-GIN.cHS4 with either pUC19 or the HSB3-encoding plasmid pCMV-HSB3 using a 40:1 plasmid ratio. The experiment was performed in triplicates and the data are presented as mean \pm SD. A mean of 7 and 90 colonies was observed in cultures transfected with pUC19 and pCMV-HSB3, respectively. (C) Five young Göttingen minipigs (pigs \#6-9 and \#13) established by SCNT. (D) GFP expression in ear cuts from the five Göttingen pigs. Ear cuts were analyzed in normal light (a, c, e, g, and i) and under blue light (b, $d, f, h$, and j). Samples were derived from the pigs (\#6-9 and \#13) indicated above each set up of pictures.

Figure 2. Genetic analysis of transgenic pigs harboring the SBT/cHS4.Ubi-GIN.cHS4 cassette. (A) Schematic map of the pSBT/cHS4.Ubi-GIN.cHS4 plasmid with relevant restriction sites, used in the Southern blot analysis, indicated by dashed lines. Restriction sites used for LDI-PCR are shown in bold and marked with arrows. The small arrowheads indicate location of primers used in the LDI-PCR. (B) Southern blot analysis of genomic DNA isolated from SBT/cHS4.Ubi-GIN.cHS4-transgenic pigs and digested with Xbal. A 670-bp neo ${ }^{r}$ fragment was used as probe. Lanes 2-6 contain Xbal-digested genomic DNA from the five SB-transgenic pigs shown in Figure 1C. Negative controls are provided in lanes 7 and 8 which contain Xbal-digested DNA from a control pig (\#78) and a porcine cell line (PFV) which did not 
contain the neor gene, respectively. Pig identification numbers are provided above each lane. Lane 1 contains a marker. (C) The transposase gene cassette could not be detected in genomic DNA. Lanes 1-5 and 8-12 represent PCR reactions performed on genomic DNA from each of the five GFP-transgenic pigs using two primer sets (one amplifying part of the CMV promoter plus upstream part of the HSB3 gene and one amplifying the HSB3 ORF). PCR reactions performed on DNA from a wildtype pig were loaded in lanes 6 and 13, whereas PCR reactions performed on genomic DNA from a control pig containing a genomic insertion of the transposase gene were included as positive controls (lanes 7 and 14).

Figure 3. Identification of SB transposon insertion sites in intergenic regions of the porcine genome. Junction sites between transposon DNA and flanking DNA were identified by LDI-PCR in transgenic pig \#8 harboring eight copies of the transgene cassette. Genomic DNA was digested with BsrGl or BsrGl/Ndel prior to PCR amplification with the primers shown in Figure 2A. Four SB insertion sites, all located in intergenic regions, were identified in pig \#8 by a Blast searching the porcine genome using sequence tags identified by LDI-PCR. For one of the insertions (indicated with ${ }^{*}$ ), only a 25 -bp sequence tag could be identified due to the short length of the LDI-PCR product. The vector insertion into chromosome 3 was flanked by a short stretch of TA-repeats which represents a potential consensus SB insertion site (Vigdal et al. 2002).

Figure 4. Systemic GFP expression in the SBT/cHS4.Ubi-GIN.cHS4-transgenic pig \#8. Organs and tissues isolated from pig \#8 and one wild type pig were analyzed by normal and blue light excitation. The left and right side of each picture shows organ/tissue from the wild type pig and the pSBT/cHS4.UbiGIN.cHS4 pig \#8, respectively. The following organs or tissues were analyzed: A, Brain; B, Rib bone; C, Skeletal muscle; D, Salivary gland; E, Tongue; F, Eye; G, Heart; H, Testis; I, Subcutaneous fat; J, Pancreas; K, Spleen; L, Bladder; M, Colon; N, Kidney; O, Lung; P, Liver, and Q, Skin. Diagrams A1 through Q1 show 
samples under normal light displayed in black and white. A2 through Q2 show samples under blue light excitation (480 $\mathrm{nm}$ ) allowing visualization of GFP. 


\section{REFERENCES}

Betthauser J, Forsberg E, Augenstein M, Childs L, Eilertsen K, Enos J, Forsythe T, Golueke P, Jurgella G, Koppang R, Lesmeister T, Mallon K, Mell G, Misica P, Pace M, Pfister-Genskow M, Strelchenko N, Voelker G, Watt S, Thompson S, Bishop M (2000) Production of cloned pigs from in vitro systems. Nat Biotechnol 18:1055-1059.

Cabot RA, Kuhholzer B, Chan AW, Lai L, Park KW, Chong KY, Schatten G, Murphy CN, Abeydeera LR, Day BN, Prather RS (2001) Transgenic pigs produced using in vitro matured oocytes infected with a retroviral vector. Anim Biotechnol 12:205-214.

Cibelli JB, Stice SL, Golueke PJ, Kane JJ, Jerry J, Blackwell C, Ponce de Leon FA, Robl JM (1998) Cloned transgenic calves produced from nonquiescent fetal fibroblasts. Science 280:1256-1258.

Ciuffi A, Llano M, Poeschla E, Hoffmann C, Leipzig J, Shinn P, Ecker JR, Bushman F (2005) A role for LEDGF/p75 in targeting HIV DNA integration. Nat Med 11:1287-1289.

Clark KJ, Carlson DF, Fahrenkrug SC (2007a) Pigs taking wing with transposons and recombinases. Genome Biol 8 Suppl 1:S13.

Clark KJ, Carlson DF, Foster LK, Kong BW, Foster DN, Fahrenkrug SC (2007b) Enzymatic engineering of the porcine genome with transposons and recombinases. BMC Biotechnol 7:42.

Dalsgaard T, Moldt B, Sharma N, Wolf G, Schmitz A, Pedersen FS, Mikkelsen JG (2009) Shielding of sleeping beauty DNA transposon-delivered transgene cassettes by heterologous insulators in early embryonal cells. Mol Ther 17:121-130.

Davidson AE, Balciunas D, Mohn D, Shaffer J, Hermanson S, Sivasubbu S, Cliff MP, Hackett PB, Ekker SC (2003) Efficient gene delivery and gene expression in zebrafish using the Sleeping Beauty transposon. Dev Biol 263:191-202. 
Du Y, Kragh PM, Zhang Y, Li J, Schmidt M, Bogh IB, Zhang X, Purup S, Jorgensen AL, Pedersen AM, Villemoes K, Yang H, Bolund L, Vajta G (2007) Piglets born from handmade cloning, an innovative cloning method without micromanipulation. Theriogenology 68:1104-1110.

Dupuy AJ, Clark K, Carlson CM, Fritz S, Davidson AE, Markley KM, Finley K, Fletcher CF, Ekker SC, Hackett PB, Horn S, Largaespada DA (2002) Mammalian germ-line transgenesis by transposition. Proc Natl Acad Sci U S A 99:4495-4499.

Garrick D, Fiering S, Martin DI, Whitelaw E (1998) Repeat-induced gene silencing in mammals. Nat Genet 18:56-59.

Hammer RE, Pursel VG, Rexroad CE, Jr., Wall RJ, Bolt DJ, Ebert KM, Palmiter RD, Brinster RL (1985) Production of transgenic rabbits, sheep and pigs by microinjection. Nature 315:680-683.

Hirabayashi M, Takahashi R, Ito K, Kashiwazaki N, Hirao M, Hirasawa K, Hochi S, Ueda M (2001) A comparative study on the integration of exogenous DNA into mouse, rat, rabbit, and pig genomes. Exp Anim 50:125-131.

Hofmann A, Kessler B, Ewerling S, Weppert M, Vogg B, Ludwig H, Stojkovic M, Boelhauve M, Brem G, Wolf E, Pfeifer A (2003) Efficient transgenesis in farm animals by lentiviral vectors. EMBO Rep 4:1054-1060.

Hyun S, Lee G, Kim D, Kim H, Lee S, Nam D, Jeong Y, Kim S, Yeom S, Kang S, Han J, Lee B, Hwang W (2003) Production of nuclear transfer-derived piglets using porcine fetal fibroblasts transfected with the enhanced green fluorescent protein. Biol Reprod 69:1060-1068.

Ivics Z, Hackett PB, Plasterk RH, Izsvak Z (1997) Molecular reconstruction of Sleeping Beauty, a Tc1-like transposon from fish, and its transposition in human cells. Cell 91:501-510.

Izsvak Z, Ivics Z (2004) Sleeping beauty transposition: biology and applications for molecular therapy. Mol Ther 9:147-156. 
Izsvak Z, Ivics Z, Plasterk RH (2000) Sleeping Beauty, a wide host-range transposon vector for genetic transformation in vertebrates. J Mol Biol 302:93-102.

Kato Y, Tani T, Sotomaru Y, Kurokawa K, Kato J, Doguchi H, Yasue H, Tsunoda Y (1998) Eight calves cloned from somatic cells of a single adult. Science 282:2095-2098.

Kragh PM, Nielsen AL, Li J, Du Y, Lin L, Schmidt M, Bogh IB, Holm IE, Jakobsen JE, Johansen MG, Purup S, Bolund L, Vajta G, Jorgensen AL (2009) Hemizygous minipigs produced by random gene insertion and handmade cloning express the Alzheimer's disease-causing dominant mutation APPsw. Transgenic Res 18:545-558.

Kragh PM, Vajta G, Corydon TJ, Purup S, Bolund L, Callesen H (2004) Production of transgenic porcine blastocysts by hand-made cloning. Reprod Fertil Dev 16:315-318.

Kubota C, Yamakuchi H, Todoroki J, Mizoshita K, Tabara N, Barber M, Yang X (2000) Six cloned calves produced from adult fibroblast cells after long-term culture. Proc Natl Acad Sci U S A 97:990-995. Lai L, Park KW, Cheong HT, Kuhholzer B, Samuel M, Bonk A, Im GS, Rieke A, Day BN, Murphy CN, Carter DB, Prather RS (2002) Transgenic pig expressing the enhanced green fluorescent protein produced by nuclear transfer using colchicine-treated fibroblasts as donor cells. Mol Reprod Dev 62:300-306.

Leahy P, Carmichael GG, Rossomando EF (1997) Transcription from plasmid expression vectors is increased up to 14 -fold when plasmids are transfected as concatemers. Nucleic Acids Res 25:449-450.

Liu G, Geurts AM, Yae K, Srinivasan AR, Fahrenkrug SC, Largaespada DA, Takeda J, Horie K, Olson WK, Hackett PB (2005) Target-site preferences of Sleeping Beauty transposons. J Mol Biol 346:161173. 
Liu L, Mah C, Fletcher BS (2006) Sustained FVIII expression and phenotypic correction of hemophilia A in neonatal mice using an endothelial-targeted sleeping beauty transposon. Mol Ther 13:10061015.

Mates L, Chuah MK, Belay E, Jerchow B, Manoj N, Acosta-Sanchez A, Grzela DP, Schmitt A, Becker K, Matrai J, Ma L, Samara-Kuko E, Gysemans C, Pryputniewicz D, Miskey C, Fletcher B, Vandendriessche T, Ivics Z, Izsvak Z (2009) Molecular evolution of a novel hyperactive Sleeping Beauty transposase enables robust stable gene transfer in vertebrates. Nat Genet 41:753-761.

Mikkelsen JG, Yant SR, Meuse L, Huang Z, Xu H, Kay MA (2003) Helper-Independent Sleeping Beauty transposon-transposase vectors for efficient nonviral gene delivery and persistent gene expression in vivo. Mol Ther 8:654-665.

Mitchell RS, Beitzel BF, Schroder AR, Shinn P, Chen H, Berry CC, Ecker JR, Bushman FD (2004) Retroviral DNA integration: ASLV, HIV, and MLV show distinct target site preferences. PLoS Biol 2:E234.

Moldt B, Staunstrup NH, Jakobsen M, Yanez-Munoz RJ, Mikkelsen JG (2008) Genomic insertion of lentiviral DNA circles directed by the yeast Flp recombinase. BMC Biotechnol 8:60.

Naruse K, Ishikawa H, Kawano HO, Ueda H, Kurome M, Miyazaki K, Endo M, Sawasaki T, Nagashima H, Makuuchi M (2005) Production of a transgenic pig expressing human albumin and enhanced green fluorescent protein. J Reprod Dev 51:539-546.

Nottle MB, Haskard KA, Verma PJ, Du ZT, Grupen CG, Mcllfatrick SM, Ashman RJ, Harrison SJ, Barlow H, Wigley PL, Lyons IG, Cowan PJ, Crawford RJ, Tolstoshev PL, Pearse MJ, Robins AJ, d'Apice AJ (2001) Effect of DNA concentration on transgenesis rates in mice and pigs. Transgenic Res 10:523-531.

Ohlfest JR, Lobitz PD, Perkinson SG, Largaespada DA (2004) Integration and long-term expression in xenografted human glioblastoma cells using a plasmid-based transposon system. Mol Ther 10:260-268. 
Onishi A, Iwamoto M, Akita T, Mikawa S, Takeda K, Awata T, Hanada H, Perry AC (2000) Pig cloning by microinjection of fetal fibroblast nuclei. Science 289:1188-1190.

Park KW, Cheong HT, Lai L, Im GS, Kuhholzer B, Bonk A, Samuel M, Rieke A, Day BN, Murphy CN, Carter DB, Prather RS (2001) Production of nuclear transfer-derived swine that express the enhanced green fluorescent protein. Anim Biotechnol 12:173-181.

Park KW, Lai L, Cheong HT, Cabot R, Sun QY, Wu G, Rucker EB, Durtschi D, Bonk A, Samuel M, Rieke A, Day BN, Murphy CN, Carter DB, Prather RS (2002) Mosaic gene expression in nuclear transferderived embryos and the production of cloned transgenic pigs from ear-derived fibroblasts. Biol Reprod 66:1001-1005.

Polejaeva IA, Chen SH, Vaught TD, Page RL, Mullins J, Ball S, Dai Y, Boone J, Walker S, Ayares DL, Colman A, Campbell KH (2000) Cloned pigs produced by nuclear transfer from adult somatic cells. Nature 407:86-90.

Schorpp M, Jager R, Schellander K, Schenkel J, Wagner EF, Weiher H, Angel P (1996) The human ubiquitin C promoter directs high ubiquitous expression of transgenes in mice. Nucleic Acids Res 24:17871788.

Schroder AR, Shinn P, Chen H, Berry C, Ecker JR, Bushman F (2002) HIV-1 integration in the human genome favors active genes and local hotspots. Cell 110:521-529.

Singh H, Manuri PR, Olivares S, Dara N, Dawson MJ, Huls H, Hackett PB, Kohn DB, Shpall EJ, Champlin RE, Cooper $\sqcup$ (2008) Redirecting specificity of T-cell populations for CD19 using the Sleeping Beauty system. Cancer Res 68:2961-2971.

Sinzelle L, Vallin J, Coen L, Chesneau A, Du Pasquier D, Pollet N, Demeneix B, Mazabraud A (2006) Generation of trangenic Xenopus laevis using the Sleeping Beauty transposon system. Transgenic Res 15:751-760. 
Staunstrup NH, Moldt B, Mates L, Villesen P, Jakobsen M, Ivics Z, Izsvak Z, Mikkelsen JG (2009) Hybrid lentivirus-transposon vectors with a random integration profile in human cells. Mol Ther $17: 1205-1214$

Tolstrup AB, Duch M, Dalum I, Pedersen FS, Mouritsen S (2001) Functional screening of a retroviral peptide library for MHC class I presentation. Gene 263:77-84.

Vigdal TJ, Kaufman CD, Izsvak Z, Voytas DF, Ivics Z (2002) Common physical properties of DNA affecting target site selection of sleeping beauty and other Tc1/mariner transposable elements. J Mol Biol 323:441-452.

Wakayama T, Shinkai Y, Tamashiro KL, Niida H, Blanchard DC, Blanchard RJ, Ogura A, Tanemura K, Tachibana M, Perry AC, Colgan DF, Mombaerts P, Yanagimachi R (2000) Cloning of mice to six generations. Nature 407:318-319.

Wakayama T, Yanagimachi R (1999) Cloning of male mice from adult tail-tip cells. Nat Genet 22:127-128.

Watanabe S, Iwamoto M, Suzuki S, Fuchimoto D, Honma D, Nagai T, Hashimoto M, Yazaki S, Sato M, Onishi A (2005) A novel method for the production of transgenic cloned pigs: electroporationmediated gene transfer to non-cultured cells and subsequent selection with puromycin. Biol Reprod 72:309-315.

Webster NL, Forni M, Bacci ML, Giovannoni R, Razzini R, Fantinati P, Zannoni A, Fusetti L, Dalpra L, Bianco MR, Papa M, Seren E, Sandrin MS, Mc Kenzie IF, Lavitrano M (2005) Multi-transgenic pigs expressing three fluorescent proteins produced with high efficiency by sperm mediated gene transfer. Mol Reprod Dev 72:68-76.

Whitelaw CB, Radcliffe PA, Ritchie WA, Carlisle A, Ellard FM, Pena RN, Rowe J, Clark AJ, King TJ, Mitrophanous KA (2004) Efficient generation of transgenic pigs using equine infectious anaemia virus (EIAV) derived vector. FEBS Lett 571:233-236. 
Wilber A, Frandsen JL, Geurts JL, Largaespada DA, Hackett PB, Mclvor RS (2006) RNA as a source of transposase for sleeping beauty-mediated gene insertion and expression in somatic cells and tissues. Mol Ther 13:625-630.

Wilmut I, Schnieke AE, McWhir J, Kind AJ, Campbell KH (1997) Viable offspring derived from fetal and adult mammalian cells. Nature 385:810-813.

Yant SR, Meuse L, Chiu W, Ivics Z, Izsvak Z, Kay MA (2000) Somatic integration and long-term transgene expression in normal and haemophilic mice using a DNA transposon system. Nat Genet 25:35-41.

Yant SR, Park J, Huang Y, Mikkelsen JG, Kay MA (2004) Mutational analysis of the N-terminal DNA-binding domain of sleeping beauty transposase: critical residues for DNA binding and hyperactivity in mammalian cells. Mol Cell Biol 24:9239-9247.

Yant SR, Wu X, Huang Y, Garrison B, Burgess SM, Kay MA (2005) High-resolution genome-wide mapping of transposon integration in mammals. Mol Cell Biol 25:2085-2094.

Yergeau DA, Johnson Hamlet MR, Kuliyev E, Zhu H, Doherty JR, Archer TD, Subhawong AP, Valentine MB, Kelley CM, Mead PE (2009) Transgenesis in Xenopus using the Sleeping Beauty transposon system. Dev Dyn 238:1727-1743.

Zayed H, Izsvak Z, Khare D, Heinemann U, Ivics Z (2003) The DNA-bending protein HMGB1 is a cellular cofactor of Sleeping Beauty transposition. Nucleic Acids Res 31:2313-2322. 


\section{ABSTRACT}

Modelling of human disease in genetically engineered pigs provides unique possibilities in biomedical research and in studies of disease intervention. Establishment of methodologies that allow efficient gene insertion by non-viral gene carriers is an important step towards development of new disease models. In this report, we present transgenic pigs created by Sleeping Beauty DNA transposition in primary porcine fibroblasts in combination with somatic cell nuclear transfer by handmade cloning. Göttingen minipigs expressing green fluorescent protein are produced by transgenesis with DNA transposon vectors carrying the transgene driven by the human ubiquitin C promoter. These animals carry multiple copies (from 8 to 13) of the transgene and show systemic transgene expression. Transgene-expressing pigs carry both transposase-catalyzed insertions and at least one copy of randomly inserted plasmid DNA. Our findings illustrate critical issues related to DNA transposon-directed transgenesis, including coincidental plasmid insertion and relatively low Sleeping Beauty transposition activity in porcine fibroblasts, but also provide a platform for future development of porcine disease models using the Sleeping Beauty gene insertion technology. 
To

Dr. Bruce Whitelaw

Editor in Chief

Transgenic Research

Dear Dr. Whitelaw

We appreciate the nice words and are grateful that the manuscript has now been finally accepted for publication in Transgenic Research.

We have considered the two specific comments mentioned and have revised the manuscript accordingly. However, regarding the first comment, we chose not to include 'immortalised'. In the work by Clark and coworkers transposition is carried out in both pig fetal fibroblasts (called PFFs in the paper) and in the immortalized pig cell line PEGE. The results that we refer to (2.5-fold increase in the presence of SB11) were created by transposition in PFFs whereas transposition in PEGE cells gave a 10-fold increase. We think that the comparison with the data from PFF is most relevant for our study and therefore did not introduce further changes in the manuscript.

Sincerely,

Jacob Giehm Mikkelsen, PhD

Corresponding author 
Colour figure (Figure 1)

Click here to download high resolution image

Jakobsen et al. Fig. 1

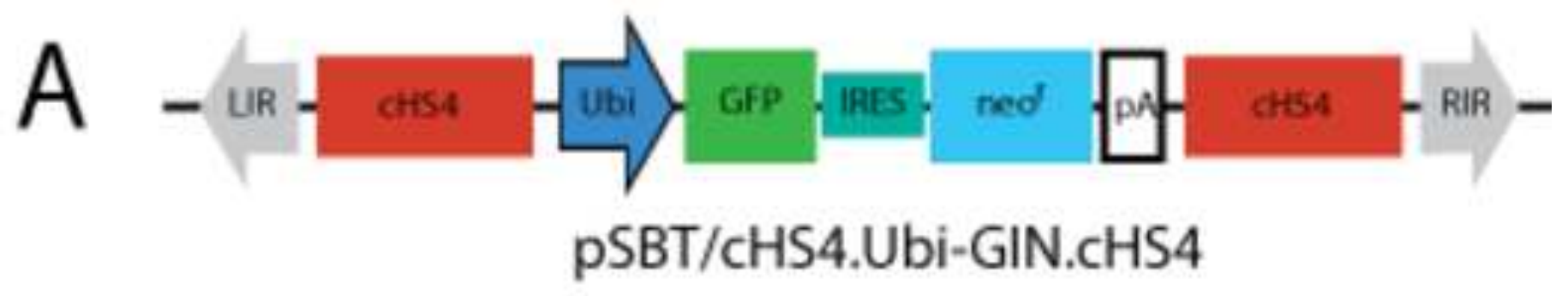

B

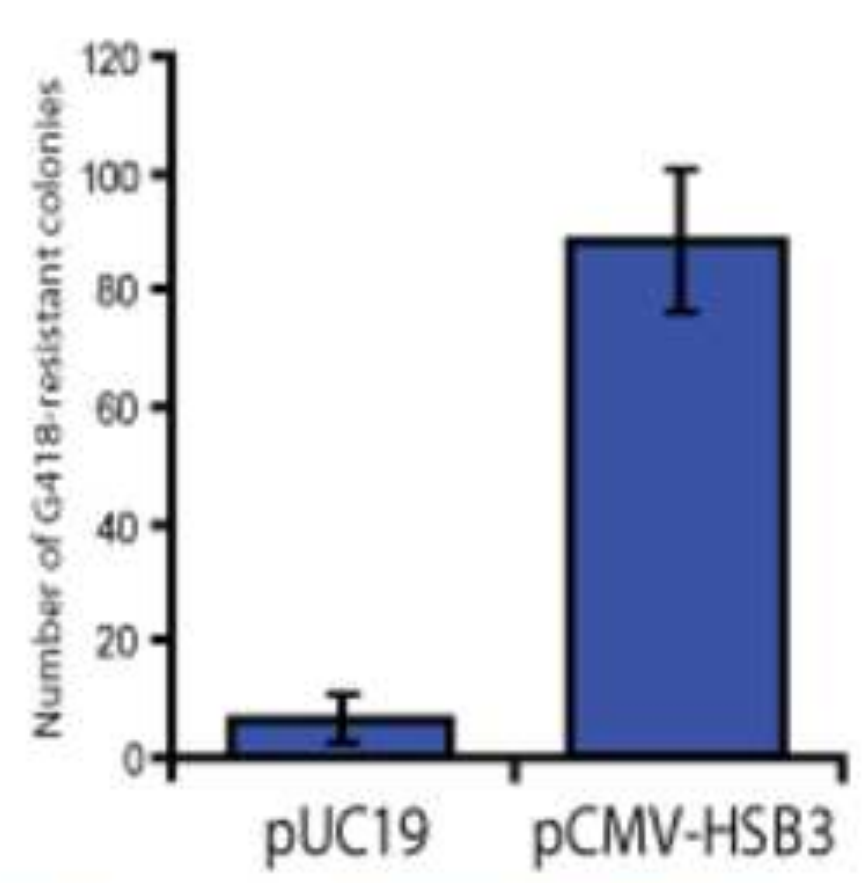

D
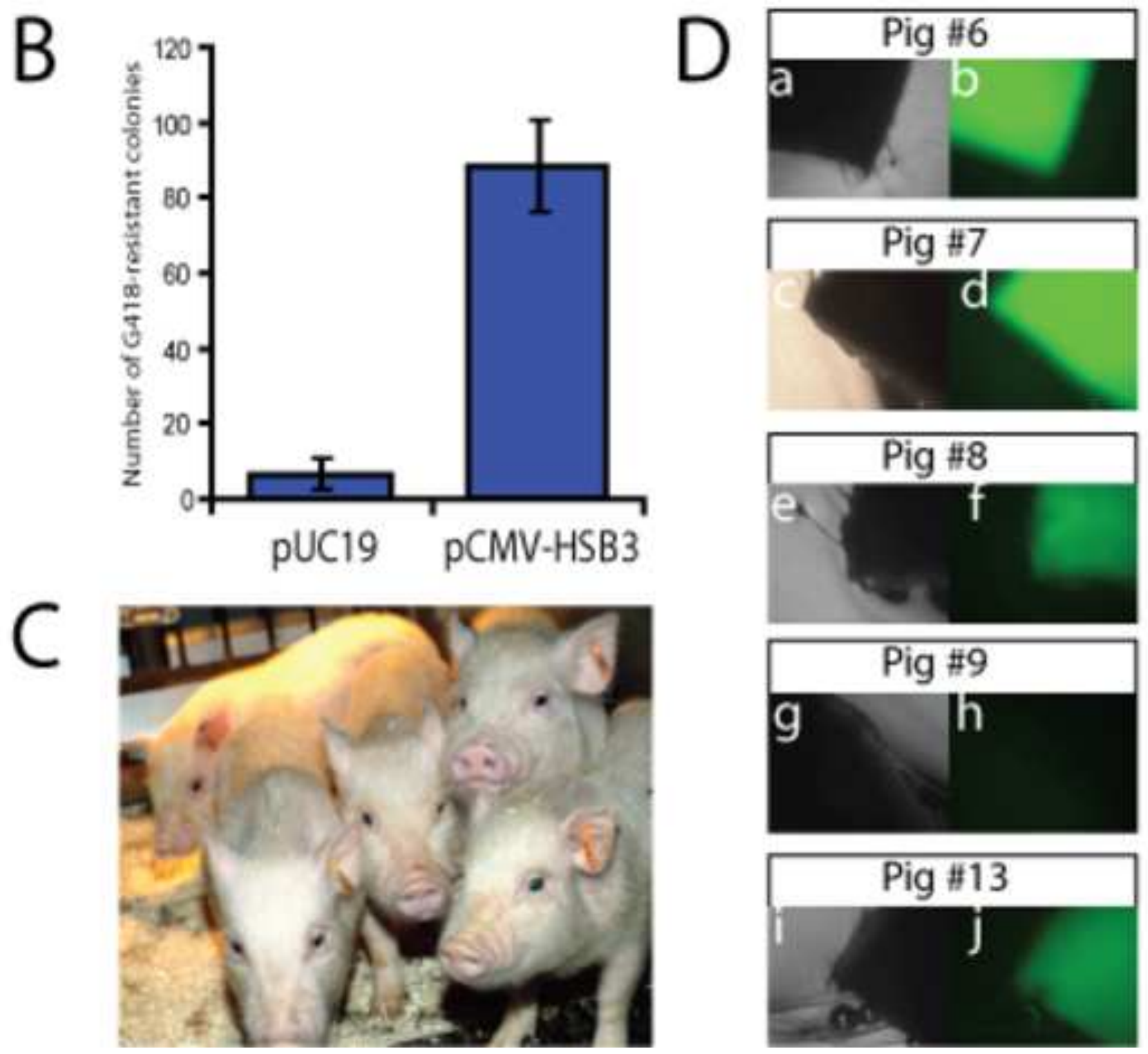

Pig \#13 


\section{Jakobsen et al. Fig. 2}
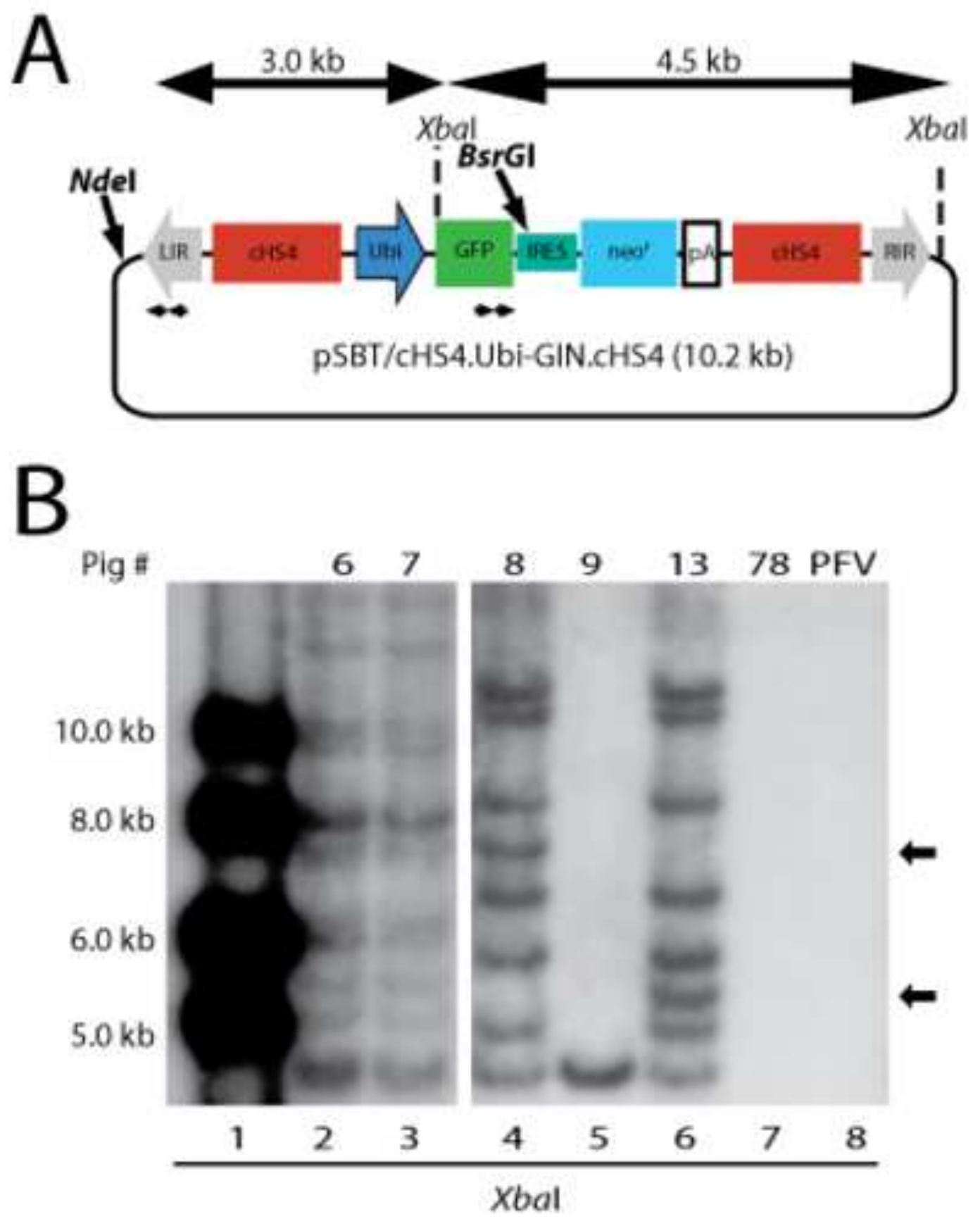

Pig \# $\begin{array}{lllllllllllllll}6 & 7 & 8 & 9 & 13 & 78 & 58 & 6 & 7 & 8 & 9 & 13 & 78 & 58\end{array}$

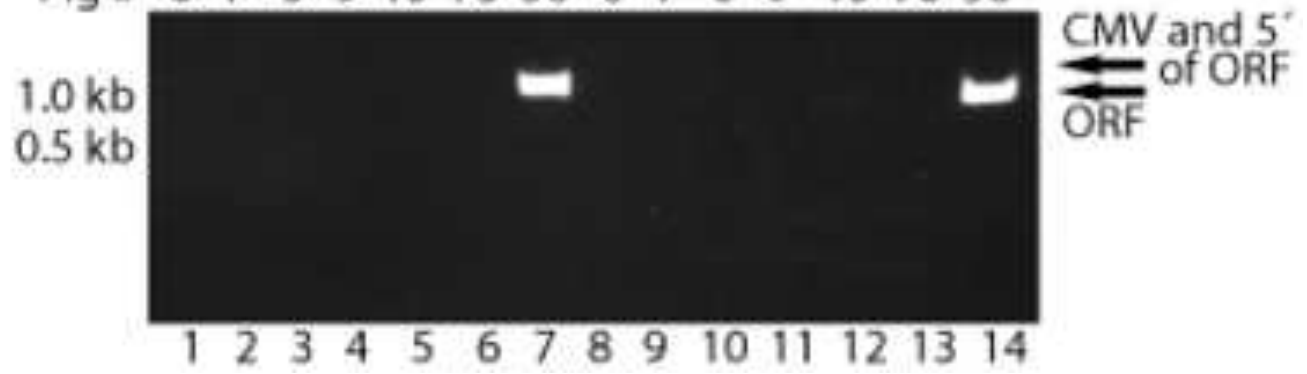


Jakobsen et al. Fig. 3

A

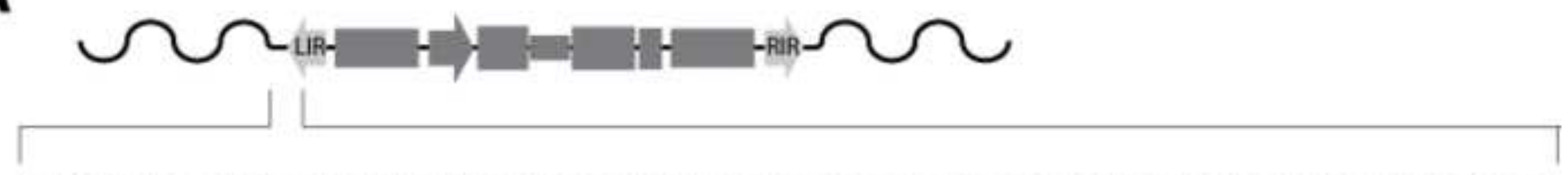

GTTGCCTIITAGGTTACAGAACTCAGCTGGGATAGGTAAACA TACAGTTGAAGTCGGAAGTTTACATAC chr 11 intergenic LIR

CAAAAATTCCACAAATGACAAGGCTCACCAGTAAAGGTATATA TACAGTTGAAGTCGGAAGTTTACATAC chr 3 intergenic LIR

ATAAACCCACATGGATATTGTTAACCCACTTATGGCAAAGAAGC TACAGTTGAAGTCGGAAGTTTACATAC chr 9 intergenic LIR

TATCACTCTCGGCATGGACGAGCTG TACAGTTGAAGTCGGAAGTTTACATAC chr $7^{*}$ intergenic 
Colour figure (Figure 4)

Click here to download high resolution image

Jakobsen et al Fig. 4
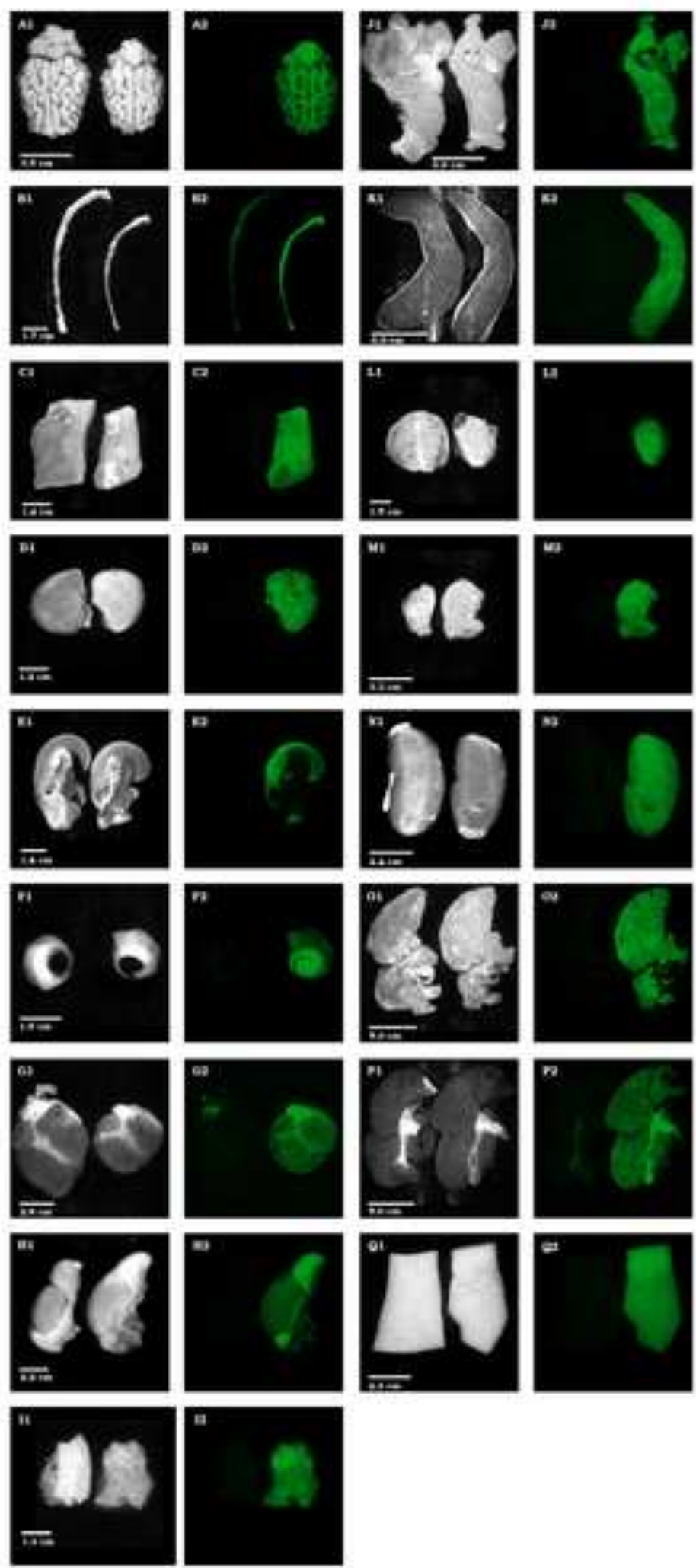